\title{
Batıda Gelenekselci Ekol Bakış Açısıyla Tasavvuf: Martin Lings Örneği
}

\section{Sufism in the West from the Perspective of the Traditionalist School: The Example of Martin Lings}

Lings, Martin. Tasavvuf Nedir?, Tercüme: Semih Ceyhan, (İstanbul, Nefes Yayıncılık, 2017).

ISBN: 978-605-9901-37-6.

\section{Cansu Yazıcı" $\odot$}

\section{Anahtar Kelimeler}

Tasavvuf, zühd, din ilimleri

Keywords

Sufism, renunciation, religious sciences

Tasavvuf, belli bir yöntemi, amacı, mizacı ve kendine has bir disiplini olan bir din bilimidir. Tasavvufun mahiyeti üzerine birçok çalışma yapılmıştır. Bu çalışmalardan biri de Martin Lings' in “Tasavvuf Nedir? " adlı kitabıdır. Lings' in, bu kitabı kaleme alma hedefinin, genelde Batıl1, özelde İngiliz okuyucu kitlesine tasavvufu tanıtmak olduğu, kendi ifadelerinden anlaşılmaktadır. "Tasavvuf Nedir? ” kitabı, önsöz ve dokuz bölümden oluşmaktadır. Lings, “Tasavvufun Menşei ve Özgünlü̆̈̈̈, Tasavvufun Evrenselliği, Kitap, Peygamber, Kalp, Doktrin, Yöntem, Tasavvufun Kendine Özgülüğ̈̈, Asırlar Boyunca Tasavvuf” şeklinde sıralanan dokuz bölümü, sembolik örneklendirmelerle sohbet havasında yazmıştır.

Önsöz kısmında, yazar, özel bilgiyi gerektirmediği düşüncesiyle eserini giriş mahiyetinde ele aldığını, eserinin maneviyatı yönüyle ilgiye layık olması gerektiğini ifade etmiştir. Bizlere göre de kitap, gerçeği en özlü bir şekilde nasıl aktarılabilecekse, o şekilde aktarmış, bu kadar ilgi görmesinin nedeni de bu olmuştur. Tasavvufu bir "zevk" olarak tanımlayan Lings'e göre, bâtının doğrudan idraki insan nefsi için imkan dahilindedir ve tasavvufun gayesi de budur. Lings, tasavvufun, istenildiğinde aranılıp bulunan bir yol olduğunu verdiği örneklerle izah etmeye çalışmış, kitabını da bunun üzerine kurmuştur.

\footnotetext{
* Sorumlu Yazar: Cansu Yazıcı, İstanbul Üniversitesi, Sosyal Bilimler Enstitüsü Tasavuf Anabilim Dalı, İstanbul, Türkiye.

E-posta: cansyzc9@gmail.com ORCID: 0000-0002-0634-562X
}

Atıf: Yazici, Cansu. "Batıda Gelenekselci Ekol Bakış Açısıyla Tasavvuf: Martin Lings Örneği." Martin Lings'in "Tasavvuf Nedir?" adlı eserinin değerlendirmesi. darulfunun ilahiyat 32, 2 (2021): 659-664. https://doi.org/10.26650/di.2021.32.2.1026706 
Tasavvufun Menşei ve Özgünlü̆̆̈̈ olarak isimlendirilen birinci bölüme yazar, açıklamak istediği kavrama öncelikle kendisine kaynak edindiği kişilerden atıf yapmak, daha sonra kavramı açıklamak suretiyle giriş yapmıştır. "Derya" sembolünden hareketle bölüme başlayan Lings'in ilk iddiasına göre vahiy, medcezir dalgalarıyla sonsuzluktan sonluya gelince tasavvufla birlikte tekrar sonsuzluğa geri dönebilir. Burada vahyi peyderpey med-cezir dalgasına benzettiği için yanlış anlaşılmalara mahal vermemek adına açıklama yapma ihtiyacı duymuştur. $\mathrm{Bu}$, kelimeleri çok iyi seçerek yazdığını ve okuyucuda da kendisinin anlatmak istediği şekilde anlaşılması için çabaladığını göstermektedir. Bu iddiasını desteklemek için Kur'ân'dan ve Tevrat'tan deliller getiren yazara göre, müslümanlar, Kadir gecesini kutlarken, aslında ezeli ve ebedi bir kutlama içerisinde bulunurlar ve metafiziksel kaynağa geri dönmeye çalışırlar. Mistiklerin yolunu zikirden geçen bir "yakaza" olarak ele alan yazar, zikrin tasavvuftaki yeri ve önemine dikkat çektikten sonra tasavvufun özgünlüğünün ilham ve vahiyle irtibatlı olduğundan dolayı bu ilmin menşeinin de aşkın ve fizikötesi olduğunu açıklamış; tasavvufun bir dinden bağımsız olarak varolduğunu söyleyenleri eleştirerek bölümü bitirmiştir (s. 60).

Yazarın, Tasavvufun Evrenselliği olarak isimlendirilen ikinci bölüme, tasavvufun dine bağlı olmadığı iddialarına "kutsal sanat" meselesi üzerinden verdiği yanıtlarla tasavvuf tanımı yaparak başlaması dikkat çekicidir. Bu bağlamda tasavvufun bir gayesinin de velâyet olduğunu öne süren yazara göre, kutsal sanat da velî de ilâhî mükemmelliğin birer tezâhürüdür (s. 62). Hem Hampi Tapınağı hem de Tac Mahal celâl ve cemâlin ulvî tezâhürleridir ve bunları tasavvufun billurlaşması şeklinde algılamamız gerekmektedir (s. 64). Bu noktada yazar, büyük camiler ile büyük sûfiler arasındaki yakınlığa da işaret etmektedir. Daire örneğiyle aynı anda birden fazla yoldan gidilemeyeceğini, tek bir yarıçap seçilerek merkeze ulaşılması gerektiğini anlatan yazar, kitabın başından itibaren üzerinde durduğu "Tasavvuf kapıya vurma sanatıdır" tanımına da bu konu içerisinde bir açıklık getirmiş olmaktadır. Ancak burada dikkat edilmesi gereken nokta "Tek bir kap1" vurgusudur. Bu benzetmeler, tasavvufun evrenselliğinin ortaya koyulması açısından önem arz etmektedir.

Kitap olarak isimlendirilen üçüncü bölüme, dünya sahiline vuran med dalgasının Kur'ân-1 Kerîm şeklini aldığını ifade ederek başlayan yazar, Kur'ân okuyanın Kur'ân'ın anlamlarına iştirak edemeyeceği itirazlarına cevap vererek devam eder. "Gelgit olayında" tasavvufun bir dalgayla Allah'a geri dönme çabası olduğunu yukarıda ifade eden yazara göre bunun yolu Kur'ân okumaktan geçmektedir. Çünkü Kur'ân'da Allah'a geri dönmek için işaretler vardır. Bu bölümde yazar, hem Kur'ân tefsiri yapmış hem de Allah'ın isimlerinin arka planda işaret ettiği anlamlarına değinip bu isimleri med dalgasına benzetmiştir (s. 72). Bu bölümde dinler arası bir karşılaştırma olduğunu, diğer dinlerde olan eksikliklerin İslam'la nasıl ve hangi 
yönden tamamlandığını anlatmaya çalışmıştır. Allah'a doğrudan ulaştırdığı için tasavvufu dosdoğru bir yol olarak tanımlayan yazara göre nefisle büyük cihat da tam anlamıyla tasavvuftur (s. 77). Son olarak sûfilerin diğer müslümanlardan farkını Kur'ân'dan dayanak getirerek ortaya koymaya çalışır ve manevi hiyerarşiyi seyr ü sülûk yapan sûfîler, inanç ve amellerine tasavvuf kokusu bulaşmamış kimseler, zahirciler olarak üç katmana ayırarak bölümü noktalar.

Peygamber olarak adlandırılan dördüncü bölüme, yazarın, Hz. Âişe (r.anha)'ın Hz. Peygamber (s.a.v.) için söylediği "Onun ahlâkı (hilkati) Kur' ân idi” ifadesiyle başlaması dikkat çekicidir. Hz. Peygamber' in dünyevî kemâlinin âhiret âleminin câzibesine gösterilen olağanüstü hassâsiyetle bütünleştiğini ve bu bütünlüğün genelde İslam özelde tasavvuf üzerinde bir iz bıraktığını anlatan yazar Batı'daki nübüvvetle ilgili eleştirilere de yanıt vermiştir. Kur'ân'daki kıyamet vurgusunu İsrâ ve Miraç olaylarıyla birlikte düşünür ve bu olayların dünyada iken Hz. Peygamber (s.a.v.)'e kıyametin yaşattırılması olduğunu, sûfilerin de bu tecrübeyi yaşadıklarını iddia etmektedir (s. 85). Lings, İslam'daki “yön bilinci” ile sûfîlerin ehl-i tarîk olmalarını bağdaştırmış, bazı ayetlere bâtın mânalar verip ayet meallerinin kelime anlamlarını ifade etmede eksik kaldığını söyleyerek bazı eklemeler yapmıştır. Bu bölümde "Rıdvan" kelimesinin ve "salavat getirmenin" üzerinde durulmuştur.

Kalp olarak adlandırılan beşinci bölüme sûfilerin sözleriyle başlayan yazar, sûfî kelimesinin kökenine dair görüşleri sıraladıktan sonra kendi görüşünü açıklar (s. 9899). Sûfi kelimesinin fakir anlamına geldiğini söyleyerek buna Kur'ân-1 Kerîm'den örnekler getirir. Ona göre kulluk ve fakirlik arasında bir irtibat vardır ve tasavvuf, kalbin uyanıklığından (yakaza) başka bir şey değildir. Arapça' da hem "göz" hem de "suyun kaynağı" anlamına gelen "ayn" kelimesiyle "kalp" kelimesi arasında kurduğu irtibat ve yine sembollerle özgün anlatımı dikkat çekicidir. Kalbî bilginin doğrudanlığını savunan yazar, burada tasavvufu bir "zevk" olarak nitelemiş ve bu kalbî bilgiyi ihsanla bağdaştırmıştır (s. 107-114). Bu bölüm yakînin derecelerinin açıklanmasıyla sona ermiştir.

Doktrin olarak adlandırılan altıncı bölüme kelime-i şehâdeti açıklayarak ve farklı anlamları sıralayarak başlayan yazara göre sadece sûfiler kelime-i şehâdet formülasyonunu en yüksek neticesine ulaştırmaya gayret ederler (s. 121). Vahdet-i vücudun doğru anlaşılması için aklın keşifle desteklenmesi gerektiğini söyleyerek vahdet-i vücud fikrini ayet, ayetlerin iniş sebepleri, hadis ve sûfi sözlerinden örnekler getirerek desteklemektedir. Tasavvuf doktrinini çalışmanın, aklı, kendi üst sınırına taşıdı ğını ve bu doktrinin amacının akıl, hayal ve nefsin diğer kuvvelerini zihne taşımak olduğunu söylemiştir. Sûfîlerin beş ilâhî hazret doktrininin olduğunu, bu doktrinin beş mertebe olmasının varlığın birliğiyle çelişmediğini söyleyip doktrinin açıklamasıyla bölümü noktalamıştır. 
Yöntem olarak adlandırılan yedinci bölüme tasavvufa dayanak sayılan iki hadisten biriyle ${ }^{1}$ başlayan yazar, daha önce açıkladığı, sûfî doktrin ve yöntemin özü olan kelime-i şehâdetin şahitliğini kimin yapacağı meselesi üzerinde durur ve bunun Allah'ın "eş-Şâhid” isminde mündemiç olduğunu söyledikten sonra sûfîlerin ifadelerinden görüşüne deliller getirir. İbadetlerin, elementlerin sembolik olduğunu iddia eden yazara göre abdest, saflaşma derecesi bahşeden ritüelin; su, rahmetin ve hayatın sembolüdür (s. 137-138). Nâfile ibâdetlerin farz ibâdetler üzerinde potansiyel bir öncelik ve üstünlüğe sahip olduğunu ancak birbirinin yerine geçmediğini düşünen yazar, yöntemi bunun üzerinden kurmaktadır (s. 139-140). Dengenin nasıl sağlanacağıyla tasavvufun ne olduğunu aynı sorunun iki versiyonu olarak düşünür ve buna cevap olarak insanın nefsinde ilahi isme yönelik bir teveccüh ortaya koyması gerektiğini, bunun kabz hâli olduğunu söyler. Kabz hâli ile 'halvet' terimini, bast hâli ile 'celvet' terimini birlikte ele alarak kabz kalktığında kemâlin devam etmesi gerektiğini, aslolanın bast hâli olduğunu söyler.

Tasavvufun mahiyetine dair en çok açıklamayı Tasavvufun Kendine Özgülüğ̈̈ bölümünde dile getiren yazar, tasavvufta zâhir-bâtın ilişkisini ele alır. Birtakım tehlikelerden bahsederek bunlardan kurtulmanın yolunun bir mürşide bağlanmak olduğunu ve her îmanlı kişinin şimdi veya daha sonra bir sûfî olacağını açıklar. Tasavvufun kendine özgülüğünün bütün hususiyetlerini Râbiatü'l-Adeviyye'nin "Varlığın diğer günahlarla kıyas kabul etmez biçimde bir günahtır" ifadesinin içinde barındırdığını ve bu kendine özgülüğünün sadece "sâlik" olmaya ehil olanlarla ilgili olduğunu (s. 159-163) iddia eden yazar, tasavvufun özgünlügünü "kapsayıcılık" ve "içselleşttirme" ile bağdaştırarak bölümü bitirir.

İslam'ın teşekkülüyle diğer dinlerin teşekkülü arasındaki farkı ortaya koymaya çalıştığı Asırlar Boyunca Tasavvuf bölümüne Lings, Allah'ın bir inâyeti olarak İslam ümmetinin en hayırlı topluluk olduğunu, ilk mürşidin Hz. Muhammed (s.a.v.) olduğunu açıklayarak başlamıştır. Hz. Peygamber (s.a.v.) döneminden başlayarak sahabe, tabiîn ve daha sonraki dönemlerdeki tasavvufi yaşam hakkında açıklamalar yapan yazar tasavvuf tarihine ve tasavvuf tarihinin Hasan el-Basrî, Râbia el-Adeviyye, Cüneyd-i Bağdâdî, Serî es-Sekatî, Ebu Yezid el-Bistâmî, Hallâc-1 Mansûr, Gazâlî, Abdulkâdir Geylânî, Ebu Medyen Şuayb el-Mağribî, Muhyiddin İbn Arâbî gibi öne çıkan isimlerine kitabında geniş yer ayırır. İbn Atâullah el-İskenderî'nin (ö. 709/1309) el-Hikemu'l-Atâiyye ve Abdülkerîm elCîlı’nin el-İnsânu'l-kâmil eserinin tasavvuf tarihinin en önemli iki kaynağı olduğunu

1 "Kulum üzerine farz kıldığım şeylerden daha iyi bir yolla bana yaklaşamaz. Kulum nafilelerle de bana yaklaşır. Ta ki ben onu severim. Onu sevince de işiten kulağı, gören gözü, tutan eli ve yürüyen ayağı olurum” Buhârî, Rikak, 38 . 
(s. 194-195) söyleyen yazar, tasavvufun orijinal mütefekkirler çıkarmadığına dair eleştirilere yanıt vererek bölümü bitirir.

Tasavvufun mahiyeti üzerine yazılan Martin Lings'in Tasavvuf Nedir? kitabının özgün, tutarlı, açık ve güçlü bir sembolik üslupla ele alındığı ve bu üslubunun kitabının başından sonuna kadar korunduğu gözlemlenmektedir. Hedef kitlesi olarak genelde Batıl1, özelde İngiliz okurları seçen Lings'in, yaptığı sembolik ve açıklamalı anlatım tarzıyla kitabını bu hedef kitleye uygun yazdığını söyleyebiliriz. İslam'daki bazı kavramları açıklamış olması da bu kitaptan Müslüman olmayan okuyucuların faydalanmasının arzu edildiğini destekler niteliktedir. "Batı ne kadar ilerlerse ilerlesin ahiretteki ilerlemeyi düşünen mistisizimdir" ifadesiyle hedef kitlesi olan Batılıların kendilerini ne kadar ilerde ve üstün görseler de bunun dünyalıktan ibaret olduğunu, asıl olanın ahiret olup bunda da sadece mistiklerin ilerleyebileceğini dile getirmiştir. Tasavvufun üstünkörü ele alınırsa kendisiyle çelişebileceğini düşünen yazar, yüzeysel olmayan ancak çok detaya da girmeyen özet bir eser kaleme almıştır.

Lings, görüşlerini desteklemek için Kur'ân-1 Kerîm'den, Tevrat’tan deliller getirir, soyut kavramları somutlaştırarak, semboller kullanarak benzetmelerde bulunur, bazı eserlerin tanıtımını yaparak içerikleri hakkında bilgi verir. Aynı zamanda şeyhlerin ifadelerinden ve tasavvuf klasiklerinden nakiller yaparak bunlara dair vukûfiyetini gösterir. Bir dilci olan yazar, dilciliğini kitabında da göstermiş, meramını en uygun şekilde anlatmak için kelimeleri iyi seçmiş ve bazen o kelimelerin anlamlarına ve neden o kelimeyi kullandığına dair açıklamalarda bulunmuştur. Her ne kadar sohbet havasında yazılmış olsa da okuyucuyu düşündüren, ideolojik, akademik ve didaktik öğeleri barındıran bir yapısı olan eser, -bazı açıklamalar dipnotlarda yapılmış olsa da- kafalardaki soru işaretlerini gidermede yeterli olamamıştır.

Tasavvufun mahiyetini anlatırken simge ve sembollerden çokça yararlanan Lings, tasavvufun vahyin simgesi olduğu iddiasını yeterli delillerle sunamasa da onun, tasavvufun bir dinden bağımsız varolduğunu söyleyenlere karşı sunduğu etkileyici simgesel açıklamalar ve akla takılabilecek soruları sorup-cevap şeklinde dile getirmesi anlatımına zenginlik katmıştır. Lings, bazı ayetlerin açıklaması için verdiği dipnotta Kur'ân'ın üslubundan da bahsetmiş, ayetlere şeriat sınırları içerisinde manalar yükleyip tefsir yapmış ve görüşlerini delillendirmek için Kur'ân'dan çokça faydalanmıştır. Kitabını "gelgit" metaforu üzerine kuran ve semboller üzerinden birçok tasavvuf tanımı yapan Lings' in tasavvufun mahiyeti hakkındaki genel düşüncesi "Tasavvuf merkezîdir, yüceltilmiştir, derindir ve esrarengizdir. Değiştirilemez mükemmeldir, güçlüdür, tehlikelidir, ulaşılması zordur ve zarûridir" ifadelerinde özetlenmiştir. 
Mütercimin dipnotları çevirdikten sonra parantez içinde Türkçe çeviri kaynaklarını göstermesi, bazı eserlerin başka baskılarını da zikretmesi kitabı incelerken birincil kaynaklara da ulaşmamızı kolaylaştırmak açısından önemlidir. Aynı zamanda müellifin kaynak göstermeden yaptığı alıntı ve atıflara, hadislere açıklamalar yine mütercim tarafından getirilmiştir. Mütercim, bu eseri sadece birebir çeviri olarak ele almamış, müellifin hayatını ve eserlerini anlatmış, ele aldığı kitabın kısaca tanıtımını yapmış ve kitap hakkındaki kendi görüşlerini aktarmıştır. Mütercimin izlemiş olduğu bu üslubu ve müellifin diğer kitaplarına olan vukufiyetiyle dipnotlarda getirdiği açıklamalar kitabın daha iyi anlaşılmasına da katkı sağlamıştır.

Tasavvuf Nedir? kitabının ilk Türkçe çevirisini Harun Şencan yapmış, 1986'da Akabe Yayınları tarafından yayımlanmıştır. Kitabın bu çevirisi değerlendirmesini yapmış olduğumuz Semih Ceyhan tarafindan yapılmış çeviriye nazaran birebir çeviri olarak ele alınmış, kitaba veya müellifin hayatına dair ek bilgilere, kitabın içeriğine dair ek açıklamlara yer verilmemiştir. Bu çevirinin içeriğini önsözden sonra şu şekilde sıralamak mümkündür; "Tasavvufun Mebdei (Orjinalliği), Tasavvufun Evrenselliği, Kitab, Elçi (Haberci), Kalb, Öğreti, Âdâb, Tasavvufun Hususi Olması (Genele Açık Olmayışı), Çağlar Boyunca Tasavvuf”. Kitabın sonunda EK olarak adlandırılan küçük bir bölümde mütercim tasavvufa dair bazı kaynaklar hakkında bilgi vererek eseri tamamlamıştır. Tasavvuf Nedir? kitabının ikinci Türkçe çevirisini ise Veysel Sezigen yapmış ve 2007'de Vural Yayınları tarafından yayımlanmıştır. Önsöz, on bir bölüm ve dua kısımlarından oluşan bu çevirinin içeriğini şu şekilde sıralamak mümkündür; "Sûfizmin Özgünlüğü, Tasavvufun Evrenselliği, Kitap, Elçi, Kalp, Doktrin, Yöntem, Sûfizmin Hususiliği, Asırlar Boyunca Tasavvuf, Tasavvufun Tabiatı ve Menşei, Bediüzzaman'ın Mektubat'ından 29. Mektup ve Dua ". ${ }^{3}$ Kitabın karşılaştırdığımız çevirileri ile değerlendirmesini yaptığımız çevirisi arasında mezkur farklılıklar olsa da ana mesaj hepsinde "Ara, bul, çal” metaforu üzerindedir. Buna göre tasavvuf yolunun arandıktan sonra bulunması ve kapısının çalınması gerekmektedir.

2 Martin Lings, Tasavvuf Nedir? Çev.: Harun Şencan, Akabe Yayınları, İstanbul, 1986.

3 Martin Lings, Tasavvuf Nedir? Çev.: Veysel Sezigen, Vural Yayınc1lık, İstanbul, 2007. 